\title{
Carcinoma de Células de Merkel Metastático: Relato de Caso
}

doi: https://doi.org/10.32635/2176-9745.RBC.2021v67n1.1107

\author{
Metastatic Merkel cell Carcinoma: Case Report \\ Carcinoma de Células de Merkel Metastásico: Relato de Caso
}

\begin{abstract}
Nathielen Caroline Schoeler'; Thayse Fachin Cormanique Kayser²; Thalita Basso Scandolara³; Rodrigo Kern'; Fernanda Mara Alves; Daniel Rech ${ }^{6}$; Carolina Panis ${ }^{7}$
\end{abstract}

\section{RESUMO}

Introduçáo: $\mathrm{O}$ carcinoma de células de Merkel é um raro tumor neuroendócrino cutâneo, que se origina das células responsáveis pela sensibilidade tátil, possui caráter agressivo, evoluçáo rápida e difícil tratamento. Relato do caso: Paciente do sexo masculino, 49 anos, caucasiano, que, ao atendimento dermatológico, apresentou nódulo indolor, infiltrando tecidos profundos, não ulcerado e localizado na região do braço esquerdo. O resultado da biópsia incisional foi positivo para carcinoma de células de Merkel. Após ressecção da lesão, os exames complementares evidenciaram doença metastática na axila e parede torácica. Com o tratamento quimioterápico, houve um benefício inicial com redução tumoral, porém, não durável, uma vez que foram reveladas novas áreas com metástases tumorais em regiôes superiores do corpo, sendo submetido a novo procedimento cirúrgico, o qual, após novo regime quimioterápico, não obteve sucesso. Conclusáo: $\mathrm{Na}$ ocasiáo do tratamento desse paciente, os anticorpos monoclonais, como o avelumab, não estavam disponíveis. O diagnóstico precoce com cirurgia de exérese da lesão imediata, antes do acometimento de outras regiōes, permanece sendo a melhor opção para um prognóstico favorável ao paciente. Contudo, a despeito disso, com as limitaçôes à época do tratamento, o paciente evoluiu a óbito.

Palavras-chave: Carcinoma de Célula de Merkel; Células de Merkel; Metástase Neoplásica; Neoplasias Cutâneas; Relatos de Casos.

\section{ABSTRACT}

Introduction: The Merkel cell carcinoma is a rare cutaneous neuroendocrine tumor that originates from cells responsible for tactile sensitivity, it has an aggressive character, fast evolution and difficult treatment. Case report: 49 years Caucasian male patient, with a painless nodule, infiltrating deep tissue, not ulcerated and located in left arm identified during the dermatological consultation. The result of the incisional biopsy was positive for Merkel cell carcinoma. After resection of the lesion, complementary exams revealed metastatic disease in the axilla and chest wall. The chemotherapy treatment brought an initial improvement with tumor reduction, however, it was not durable, because new areas with tumor metastases in upper regions of the body were revealed, the patient was submitted to an another surgical procedure, after which a new chemotherapy regimen failed. Conclusion: At the time of the treatment of this patient, monoclonal antibodies, such as avelumab, were not available. Early diagnosis with immediate lesion excision surgery, before the involvement of other regions, remains the best option for a better prognosis. However, regardless of this, because of the limitations at the time of the treatment, the patient died.

Key words: Carcinoma, Merkel Cell; Merkel Cells; Neoplasm Metastasis; Skin Neoplasms; Case Reports.

\section{RESUMEN}

Introducción: El carcinoma de células de Merkel es un tumor neuroendocrino cutáneo raro, que se origina en células responsables de la sensibilidad táctil, tiene un carácter agresivo, una evolución rápida y un tratamiento difícil. Relato del caso: Paciente masculino, de 49 años, caucásico, que en atención dermatológica encontró nódulo indoloro, infiltrando tejidos profundos, no ulcerados y ubicados en la región del brazo izquierdo. El resultado de la biopsia incisional fue positivo para el carcinoma de células de Merkel. Después de la resección de la lesión, los exámenes complementarios mostraron enfermedad metastásica en la axila y la pared torácica. Con el tratamiento de quimioterapia, hubo un beneficio inicial con la reducción del tumor, sin embargo, no es duradero, ya que se revelaron nuevas áreas con metástasis tumorales en las regiones superiores del cuerpo, que se sometieron a un nuevo procedimiento quirúrgico, que después de un nuevo régimen de quimioterapia no tuvo éxito. Conclusión: En el momento del tratamiento de este paciente, los anticuerpos monoclonales, como avelumab, no estaban disponibles. El diagnóstico temprano con cirugía para la escisión de la lesión inmediata, antes de la participación de otras regiones, sigue siendo la mejor opción para un pronóstico favorable para el paciente. Sin embargo, a pesar de esto, con las limitaciones al momento del tratamiento, el paciente falleció.

Palabras clave: Carcinoma de Células de Merkel; Células de Merkel; Metástasis de la Neoplasia; Neoplasias Cutáneas; Informes de Casos.

\footnotetext{
${ }^{1-7}$ Universidade Estadual do Oeste do Paraná. Francisco Beltrão (PR), Brasil.

'E-mail: natyschoeler@gmail.com. Orcid iD: https://orcid.org/0000-0002-5501-1730

2E-mail: thayse-c@hotmail.com. Orcid iD: https://orcid.org/0000-0003-0774-8946

${ }^{3}$ E-mail: thalitascandolara@hotmail.com. Orcid iD: https://orcid.org/0000-0003-4709-9207

${ }^{4}$ E-mail: rodrigokern1@gmail.com. Orcid iD: https://orcid.org/0000-0003-3154-0088

${ }^{5}$ E-mail: fernandamaraalves@gmail.com. Orcid iD: https://orcid.org/0000-0001-8464-1646

${ }^{6}$ E-mail: dr.rech@gmail.com. Orcid iD: https://orcid.org/0000-0002-2654-4562

7E-mail: carolpanis@hotmail.com. Orcid iD: https://orcid.org/0000-0002-0104-4369

Endereço para correspondência: Carolina Panis. Universidade Estadual do Oeste do Paraná. Laboratório de Biologia de Tumores. Rodovia Vitório Traiano km 2 -

Água Branca. Francisco Beltrão (PR), Brasil. CEP 85601-010. E-mail: carolpanis@hotmail.com
} 


\section{INTRODUÇÃO}

As células de Merkel, descobertas em 1875, são responsáveis pela sensibilidade tátil ${ }^{1}$ e derivam de células-tronco pluripotentes epidérmicas ${ }^{2}$. Raramente, essas células tornam-se neoplásicas, originando o carcinoma de células de Merkel (CCM $)^{3}$. A neoplasia desenvolve-se rapidamente na pele cronicamente danificada pelo sol. O tumor cresce geralmente de forma hemisférica e centrífuga, insinuando-se na profundidade, de modo que a epiderme integra é tensionada, infiltrando-se pelos tecidos. Infrequentemente ulcera, porém as metástases satélites podem ocorrer precocemente ${ }^{2,4}$. O CCM é confundido com metástases de carcinoma de pequenas células pulmonar, linfomas de células $\mathrm{B}$ e melanomas anaplásicos, cuja incidência permanece rara $^{1}$, e parece estar relacionado a condiçóes como imunossupressão, danos induzidos pelos raios solares ultravioleta e infecção pelo vírus da imunodeficiência humana (HIV) e pelo poliomavírus de células de Merkel $(\mathrm{MCPyV})^{5}$.

Pela raridade dessa doença, este relato de caso possui como objetivo descrever um caso de CCM, que afetou um paciente em idade precoce, náo sendo usual ao que se relata na literatura.

\section{RELATO DO CASO}

Trata-se de um estudo de caso de indivíduo único, no qual a seleção do paciente foi feita em virtude da raridade da neoplasia, realizada no Hospital do Câncer de Francisco Beltrão (Ceonc), Paraná, Brasil. A pesquisa iniciou-se mediante aplicação de Termo de Consentimento Livre e Esclarecido (TCLE) e da aprovação pelo Comitê de Ética em Pesquisa (CEP), CAAE no. 34323220.8.0000.0107. Foi realizada consulta de prontuário para obtenção de dados clinicopatológicos, e revisão de literatura sobre o tema nas plataformas PubMed e SciELO, incluindo-se todos os estudos publicados em todo período disponível. Preservou-se o anonimato do paciente.

Paciente V.T, 49 anos, branco, masculino, procedente de Francisco Beltrão-PR, solteiro, previamente hígido. No início de 2014, procurou atendimento dermatológico por causa da presença de um nódulo indolor, infiltrando em tecidos profundos, náo ulcerado e localizado na regiáo do braço esquerdo. $\mathrm{Na}$ ocasiáo, a tomografia computadorizada de tórax com contraste confirmou massa de aspecto nodal em regiâo axilar esquerda, medindo $13 \times 9 \times 6 \mathrm{~cm}$ (Figura 1). O referido exame mostrou espaço pleural conservado, transparência normal do parênquima pulmonar, ausência de massa mediastinais ou peri-hilares, brônquios principais pérvios com situação, calibre contornos e dimensôes normais.
Ainda, a tomografia computadorizada de abdome e pelve não identificou sinais de lesão-alvo.

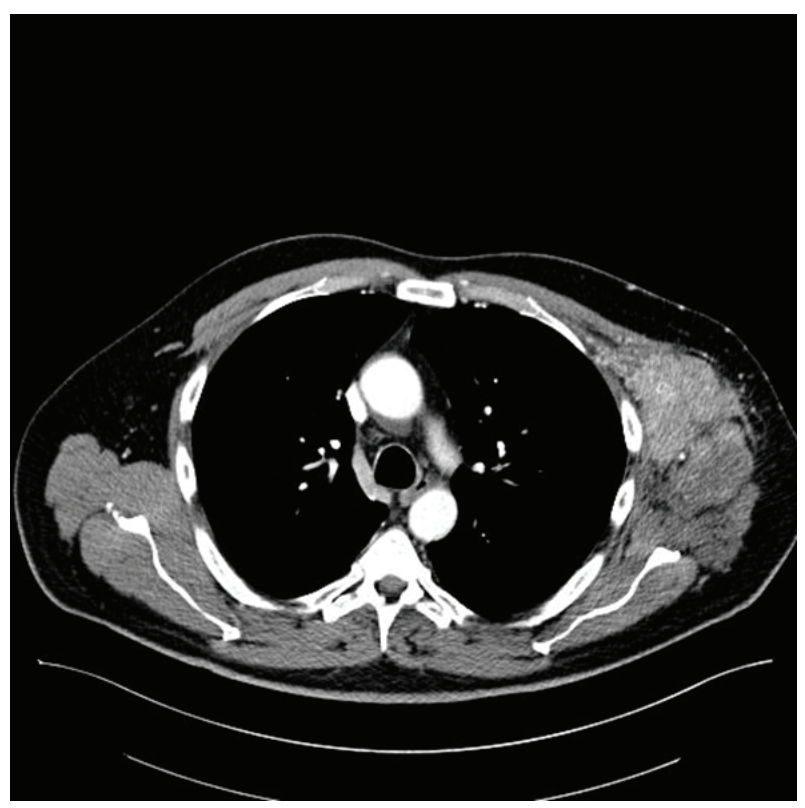

Figura 1. Imagem de tomografia computadorizada, apresentando massas nodais axilares à esquerda

Foi indicada biópsia incisional, a qual foi sugestiva de CCM, considerando-se a ausência de histórico de carcinoma neuroendócrino em outro sítio anatômico. Realizou-se exame imuno-histoquímico da biópsia incisional, sendo a imunomarcação positiva para citoqueratina 20 (CK20), que juntamente com as características observadas no exame histopatológico determinaram o diagnóstico de CCM.

Em fevereiro de 2014, o paciente foi encaminhado para ressecçẫo da lesão, realizada no hospital A. C. Camargo, em São Paulo-SP. Não há registros claros sobre a ampliação das margens e linfadenectomia sentinela, considerando que precocemente apresentou infiltração linfonodal em região axilar e supraclavicular homolateral. Diante da suspeita de doença persistente, o paciente foi submetido a demais exames complementares que evidenciaram nódulos axilares fusionados indicativos de metástases e infiltração em parede torácica. Nesse contexto de doença metastática (M1), foram indicados seis ciclos de quimioterapia com cisplatina e etoposídeo com início em setembro de 2014. Ao final do tratamento, atingiu-se o benefício considerado máximo, com redução tumoral de $25 \%$.

Em janeiro de 2015, um PET-CT evidenciou concentração anômala do $18 \mathrm{~F}-\mathrm{FDG}$ em região craniocervical (pilar amigdaliano à esquerda e linfonodos cervicais bilateralmente); torácica (linfonodo infraclavicular e volumosa formaçáo expansiva de partes moles na axila à esquerda, com extensão infraclavicular e 
parede torácica lateral); e esquelética (densificação cutânea na face posterior do cotovelo à esquerda).

No mês seguinte, o paciente foi submetido à linfadenectomia axilar e supraclavicular esquerda, associada à exérese de massa tumoral. $\mathrm{O}$ material, em monobloco cirúrgico, media $21 \times 12 \times 11,5 \mathrm{~cm}$ e pesava 1.890 gramas, estando acompanhado de tecido muscular estriado. Na periferia, encontraram-se outras dez formaçóes nodulares, a maior medindo $2,8 \mathrm{~cm}$. O laudo anatomopatológico revelou neoplasia maligna de pequenas células (CCM) com extensas áreas de necrose, infiltrando dez linfonodos dissecados e comprometendo tecidos linfoides, conjuntivo fibroso e adiposo.

Os dados clinicopatológicos do paciente encontram-se descritos na Tabela 1 .

Tabela 1. Caracterização clinicopatológica do paciente

\begin{tabular}{|c|c|}
\hline Gênero & Masculino \\
\hline Idade & 49 anos \\
\hline Raça ou cor & Branca \\
\hline Profissão & Assistente administrativo \\
\hline Escolaridade & Superior completo \\
\hline Tabagismo & Não \\
\hline Alcoolismo & Não \\
\hline $\begin{array}{l}\text { Histórico familial } \\
\text { de câncer }\end{array}$ & Sim \\
\hline Anatomopatológico & $\begin{array}{l}\text { Linfadenectomia axilar e } \\
\text { clavicular esquerda (em } \\
\text { monobloco): carcinoma } \\
\text { de células de Merkel, } \\
\text { de pequenas células } \\
\text { com extensas áreas } \\
\text { de necrose infiltrando } \\
\text { linfonodos dissecados e } \\
\text { comprometendo tecidos } \\
\text { linfoide, conjuntivo fibroso e } \\
\text { adiposo. Invasão perineural } \\
\text { presente com pele e tecido } \\
\text { muscular esquelético livre de } \\
\text { neoplasia }\end{array}$ \\
\hline $\begin{array}{l}\text { Punção aspirativa } \\
\text { de líquor }\end{array}$ & $\begin{array}{l}\text { Citologia oncótica negativa } \\
\text { e para células malignas, } \\
\text { com aspectos citológicos } \\
\text { compatíveis com processo } \\
\text { inflamatório }\end{array}$ \\
\hline $\begin{array}{l}\text { Regime de } \\
\text { tratamento }\end{array}$ & $\begin{array}{l}\text { Cisplatina e etoposídeo } \\
\text { Esquema CAV } \\
\text { (ciclofosfamida, } \\
\text { doxorrubicina e vincristina) }\end{array}$ \\
\hline Recidiva & $\begin{array}{l}\text { Sim, em região torácica/ } \\
\text { axilar esquerda }\end{array}$ \\
\hline
\end{tabular}

Realizou-se imuno-histoquímica de biópsia de linfonodo axilar esquerdo e, com base no painel encontrado (Tabela 2), concluiu-se tratar-se de um CCM metastático.

Tabela 2. Dados do exame imuno-histoquímico da biópsia

\begin{tabular}{cc}
\hline Marcadores & Resultado \\
\hline AE1/AE3 & Positivo \\
Cromogranina A & Positivo \\
Sinaptofisina & Positivo \\
CK20 & Positivo \\
MCPyV & Positivo \\
Melan-A & Negativo \\
\hline
\end{tabular}

Nota: Exame realizado pelo paciente em 2015, conclusivo para carcinoma de células de Merkel metastático.

Em março de 2015, o paciente realizou uma ultrassonografia na qual encontraram-se múltiplas imagens nodulares na transição da região cervicotorácica à esquerda e entre as linhas axilares média e posterior, além de edema difuso do tecido celular subcutâneo das regiōes analisadas. Foi indicada quimioterapia paliativa com ciclofosfamida, doxorrubicina e vincristina (CAV). Após o $4^{\circ}$ ciclo, a evidente progressão da doença e a baixa performance impediram a finalização do tratamento.

\section{DISCUSSÃO}

O CCM é uma doença agressiva, com rápida infiltração dos tecidos e metástases precoces, que atinge, em sua maioria, homens caucasianos, de idade avançada, em locais que geralmente sofrem com exposiçôes contínuas a raios ultravioleta, como membros superiores ${ }^{6}$. O perfil epidemiológico do paciente apresentado neste estudo é semelhante aos relatados na literatura - sexo masculino, caucasiano e lesôes em membros aéreos - embora o paciente não se enquadre no perfil de idade avançada (70 anos ou mais) $)^{7}$.

A progressão clínica de sobrevida de aproximadamente 12 meses após descoberta de metástases linfonodais já foi evidenciada em outros estudos, sendo que pacientes com metástases em linfonodos clinicamente comprovadas possuem um pior prognóstico em razão de se enquadrarem no estádio clínico IV, em que a taxa de sobrevida em cinco anos possui um índice inferior a $25 \% 0^{6,7}$.

Frente à suspeita de CCM, é imprescindível a análise imuno-histoquímica para o diagnóstico. $\mathrm{O}$ resultado positivo na imuno-histoquímica para MCPyV se encontra de acordo com a revisão literária, sendo associado a 
cerca de $80 \%$ dos casos de $\mathrm{CCM}^{8}$. Além disso, $\mathrm{MCPyV}$ positivos tendem a desenvolver lesóes nas extremidades, como o paciente em estudo, ao contrário de pacientes $\mathrm{MCPyV}$ negativos, com frequência maior de lesóes na cabeça e pescoço?.

Náo foram encontradas informaçóes acerca do motivo da não realização de tratamento radioterápico em conjunto da cirurgia primária e ressecçáo, considerando que o CCM ainda era uma doença restrita ao sítio anatômico de origem. Em 2016, foi aprovado pelo Food and Drug Administration (FDA) o uso do avelumab, um anticorpo monoclonal imunoglobulina G1(IgG1), que se liga à proteína de morte programada ligante 1 (PD-L1), provocando inibiçáo das células T CD-8, necessárias para a proliferação tumoral, e, com isso, abranda a resposta imunológica envolvida na patogênese do CCM, sendo eficaz ao tratamento ${ }^{2,10}$. Entretanto, na época, ainda não se dispunha dessa terapia.

Sendo assim, o paciente iniciou quimioterapia após evidência de metástases, utilizando cisplatina + etoposídeo, obtendo um resultado coerente com o já encontrado na literatura: benefício inicial com redução tumoral, porém não durável, já que poucos meses depois foram reveladas novas áreas metastáticas difundidas na região superior do corpo, classificando-o em estádio IV. Posteriormente, para a recorrência, utilizou-se o esquema CAV de quimioterapia, geralmente para câncer de pulmão; mas, por similaridades histopatológicas e citoquímicas, foi aplicado ao CCM, embora apenas com intuito paliativo ${ }^{7}$. Apesar disso, o regime quimioterápico náo interrompeu a progressão da doença e necessitou ser interrompido, tendo o paciente evoluído a óbito.

\section{CONCLUSÃO}

Considerando a baixa incidência desse tipo de neoplasia, bem como a considerável carência de informaçóes a respeito de um tratamento efetivo e bem estabelecido na literatura, as terapias a serem utilizadas para tratamento se tornam extremamente restritas. $\mathrm{O}$ diagnóstico precoce com cirurgia para exérese da lesão em caráter de urgência, antes do acometimento de outras regiôes, permanece sendo a melhor forma de prognóstico favorável ao paciente. Neste relato de caso, as principais características corresponderam às encontradas na literatura, com exceção do diagnóstico, que, contrariando as estatísticas, foi precoce.

\section{CONTRIBUIÇÕES}

Todos os autores contribuíram na concepção el ou no planejamento do estudo; na obtençáo, análise e interpretação dos dados; assim como na redação e revisão crítica; e aprovaram a versão final a ser publicada.

\section{AGRADECIMENTOS}

Ao paciente e a seus familiares pelo fornecimento dos dados e autorizaçáo para confecção do relato de caso.

\section{DECLARAÇÃO DE CONFLITO DE INTERESSES}

Nada a declarar.

\section{FONTES DE FINANCIAMENTO}

Não há.

\section{REFERÊNCIAS}

1. Saini AT, Miles BA. Merkel cell carcinoma of the head and neck: pathogenesis, current and emerging treatment options. Onco Targets Ther. 2015;8:2157-67. doi: https://doi.org/10.2147/OTT.S72202

2. Houben R, Schrama D, Becker JC. Molecular pathogenesis of Merkel cell carcinoma. Exp Dermatol. 2009;18(3):193-8. doi: https://doi. org/10.1111/j.1600-0625.2009.00853.x

3. Toker C. Trabecular carcinoma of the skin. Arch Dermatol. 1972;105(1):107-10. doi: https://doi. org/10.1001/archderm.1972.01620040075020

4. Poulsen M. Merkel cell carcinoma of skin: diagnosis and management strategies. Drugs Aging. 2005;22(3):219-29. doi: https://doi.org/10.2165/00002512-200522030-00004

5. Priante AM, Alves FV, Taborda MF, et al. Carcinoma de células de Merkel em pele de face. Rev Bras Oncol Clin [Internet]. 2012 [acesso 2020 mar 3];8(28):8890. Disponível em: https://www.sboc.org.br/sboc-site/ revista-sboc/pdfs/28/artigo5.pdf

6. Becker JC. Merkel cell carcinoma. Ann Oncol. 2010;21(Suppl 7):vii81-5. doi: https://doi.org/10.1093/ annonc/mdq366

7. Tetzlaff MT, Nagarajan P. Update on Merkel cell carcinoma. Head Neck Pathol. 2018;12(1):31-43. doi: https://doi.org/10.1007/s12105-018-0898-2

8. Feng H, Shuda M, Chang Y, et al. Clonal integration of a polyomavirus in human Merkel cell carcinoma. Science. 2008;319(5866):1096-100. doi: https://doi. org/10.1126/science.1152586

9. Sunshine JC, Jahchan NS, Sage J, et al. Are there multiple cells of origin of Merkel cell carcinoma?. Oncogene. 2018;37(11):1409-16. doi: https://doi.org/10.1038/ s41388-017-0073-3

10. D'Angelo SP, Bhatia S, Brohl AS, et al. Avelumab in patients with previously treated metastatic Merkel cell 
carcinoma: long-term data and biomarker analyses from the single-arm phase 2 JAVELIN Merkel 200 trial. J Immunother Cancer. 2020;8(1):e000674. doi: https:// doi.org/10.1136/jitc-2020-000674

Recebido em 19/6/2020

Aprovado em 16/9/2020 